\title{
Electroneutrality Coupling of Electron Transfer at an Electrode Surface and Ion Transfer across the Interface between Thin-layer of 1-Octyl-3-methylimidazolium Bis(perfluoroalkylsulfonyl)imide Covering the Electrode Surface and an Outer Electrolyte Solution
}

\author{
Kazuyuki TANAKA, Naoya NiSHI, and Takashi KAKIUCHI ${ }^{\dagger}$ \\ Department of Energy and Hydrocarbon Chemistry, Graduate School of Engineering, Kyoto University, \\ Nishikyoku, Kyoto 615-8510, Japan
}

\begin{abstract}
The electrode reaction of decamethylferrocene (DMFc) dissolved in a thin layer of a room-temperature molten salt (RTMS), 1-octyl-3-methylimidazolium bis(trifluoromethylsulfonyl)imide $\left(\mathrm{C}_{8} \mathrm{mimC}_{1} \mathrm{C}_{1} \mathrm{~N}\right)$ or 1-octyl-3methylimidazolium bis(pentafluoroethylsulfonyl)imide $\left(\mathrm{C}_{8} \operatorname{mimC}_{2} \mathrm{C}_{2} \mathrm{~N}\right)$, on a self-assembled monolayer-modified gold electrode is coupled with the ion transfer across the interface between the RTMS and the outer aqueous solution (W) to give a voltammogram whose shape resembles a voltammogram of a simple one-electron transfer process. The electroneutrality of the RTMS layer during the oxidation of DMFc to decamethylferricenium ion is maintained by the concomitant dissolution of $\mathrm{C}_{8} \mathrm{mim}^{+}$ion from the RTMS phase to the $\mathrm{W}$ phase, and the reduction of decamethylferricenium ion to DMFc is accompanied by the transfer of either $\mathrm{C}_{1} \mathrm{C}_{1} \mathrm{~N}^{-}$or $\mathrm{C}_{2} \mathrm{C}_{2} \mathrm{~N}^{-}$from RTMS to W. The midpoint potential of the voltammogram varies with the concentration of the salt in the aqueous phase, $\mathrm{C}_{8} \mathrm{mimCl}$ or $\mathrm{LiC}_{\mathrm{n}} \mathrm{C}_{\mathrm{n}} \mathrm{N}(n=1$ or 2$)$, in a Nernstian manner, showing that the phase-boundary potential between the RTMS and the W is controlled by the partition of these ions. Although the phase-boundary potential across the RTMS | W interface is Nernstian with respect to the ions common to both phases at the equilibrium, the polarization at the RTMS | W interface under current flow distorts the shape of the voltammograms, resulting in a wider peak separation in the voltammogram.
\end{abstract}

(Received August 26, 2004; Accepted September 1, 2004)

\section{Introduction}

An electrode covered with a thin layer of liquid immiscible with water has been utilized to study electron transfer across a liquid | liquid interface ${ }^{1-7}$ and the mechanism of the reduction of quinones on the electrode. ${ }^{8}$ Such a thin-layer covered electrode is geometrically the simplest variant of the electrode systems that consist of three distinct sections: a metallic conductor, an organic layer, and an aqueous solution. Some other examples of such three-phase electrode systems are electrodes with a single organic microdroplet ${ }^{9}$ or a large droplet, ${ }^{10,11}$ as well as those with many spread oil droplets ${ }^{12}$ on the electrode surface, all dipped in an electrolyte solution. A system composed of a thin liquid phase sandwiched by two aqueous phases ${ }^{13,14}$ may also be included in the group of three-phase electrode systems.

In thin-layer modified electrodes, the potential drop across the interface between the thin layer and the adjacent aqueous phase $\left(\Delta_{\mathrm{M}}^{\mathrm{W}} \phi\right)$ is one of the crucial factors that determine the overall electrochemical response of the tripartite electrode systems. Generally, $\Delta_{\mathrm{M}}^{\mathrm{W}} \phi$ does not necessarily stay constant during electrolysis, ${ }^{13,15}$ and hence may not be controllable. Two main reasons for this are the change in $\Delta_{\mathrm{M}}^{\mathrm{W}} \phi$ and the solution resistance, both of which vary with time, depending on the measurement method. This problem may be circumvented, if

$\doteqdot$ To whom correspondence should be addressed. the concentration of the potential determining ion prevails throughout the course of a measurement over those of other ions that can contribute to $\Delta_{\mathrm{M}}^{\mathrm{W}} \phi$. For this purpose, a layer of a roomtemperature molten salt (RTMS, also called an ionic liquid) instead of an organic solvent layer on the electrode is promising, in that the concentration of the potential-determining ions is inherently high in the RTMSs of the non-polarized type ${ }^{16}$ and the $\Delta_{\mathrm{M}}^{\mathrm{W}} \phi$ is Nernstian with respect to the ions commonly distributed between the RTMS and W. ${ }^{16,17}$

In this paper, we report the electrochemical properties of a gold electrode covered with a layer of an RTMS. RTMSs that are immiscible with water do not wet a gold surface, as is the case of a graphite surface. ${ }^{18}$ We therefore used a gold surface modified with a self-assembled monolayer (SAM). We will show that $\Delta_{\mathrm{M}}^{\mathrm{W}} \phi$ is potentiometrically reversible to the ions commonly distributed to both the RTMS and W phases, but is voltammetrically polarized to some extent to deform the shape of voltammograms, even at a moderate scan rate.

\section{Experimental}

\section{Reagents}

1-Octyl-3-methylimidazolium chloride $\left(\mathrm{C}_{8} \mathrm{mimCl}\right)$ was synthesized from 1-methylimidazole (Wako Pure Chem., 98+\%) and 1-chlorooctane (Aldrich 99\%) from a literature method. ${ }^{19}$ 1-Octyl-3-methylimidazolium bis(trifluoromethylsulfonyl)imide 
$\left(\mathrm{C}_{8} \mathrm{mimC}_{1} \mathrm{C}_{1} \mathrm{~N}\right)$ and 1-octyl-3-methylimidazolium bis(perfluoroethylsulfonyl)imide $\left(\mathrm{C}_{8} \operatorname{mimC}_{2} \mathrm{C}_{2} \mathrm{~N}\right)$ were prepared by mixing equimolar amounts of aqueous $\mathrm{C}_{8} \mathrm{mimCl}$ and aqueous lithium bis(trifluoromethylsulfonyl)imide $\left(\mathrm{LiC}_{1} \mathrm{C}_{1} \mathrm{~N}\right)$ or lithium bis(perfluoroethylsulfonyl)imide $\left(\mathrm{LiC}_{2} \mathrm{C}_{2} \mathrm{~N}\right)$ solutions. $\mathrm{LiC}_{1} \mathrm{C}_{1} \mathrm{~N}$ and $\mathrm{LiC}_{2} \mathrm{C}_{2} \mathrm{~N}$ were obtained from Central Glass Co. Ltd. (Japan). The RTMSs were repeatedly washed with water until no $\mathrm{Cl}^{-}$was detected when a drop of an $\mathrm{AgNO}_{3}$ solution was added to the aqueous phase. 2-Aminoethanethiol (AET; Tokyo Kasei, Japan) and decamethylferrocene (DMFc; Wako Chem. Ind. Ltd., Tokyo) were used without further purification. Other chemicals were of reagent grade.

Gold (99.99\%) was vapor-deposited on a freshly-cleaved mica sheet at a reduced pressure, $<1.3 \times 10^{-3} \mathrm{~Pa}$. The temperature of the mica sheet was maintained at $580^{\circ} \mathrm{C}$ during the vapor deposition. The Au-deposited mica sheet was subsequently annealed at $550^{\circ} \mathrm{C}$ for $8 \mathrm{~h}$ and then quenched in water. The substrate was further washed with ethanol and then water before drying under a stream of dry argon gas. The SAM of AET was formed by immersing the substrate in a $1 \mathrm{mmol} \mathrm{dm}^{-3}$ ethanol solution of AET for $24 \mathrm{~h}$.

\section{Measurements}

The contact angle $(\theta)$ of a droplet placed on a SAM-coated substrate was measured with a video imaging technique. ${ }^{20}$ $\mathrm{C}_{8} \mathrm{mimC}_{1} \mathrm{C}_{1} \mathrm{~N}$ and $\mathrm{C}_{8} \mathrm{mimC}_{2} \mathrm{C}_{2} \mathrm{~N}$ did not wet bare gold surface. These RTMSs also did not wet both hydrophobic and highly hydrophilic surfaces, such as a hexanethiol SAM and a mercaptoethanesulfonic acid $\operatorname{SAM}\left(\theta \simeq 40\right.$ and $22^{\circ}$, respectively). This is in line with the fact that hydrophobic RTMSs are immiscible not only with water, but with nonpolar or weakly polar solvents. ${ }^{21}$ We found that the values of $\theta$ of $\mathrm{C}_{8} \mathrm{mimC}_{1} \mathrm{C}_{1} \mathrm{~N}$ and $\mathrm{C}_{8}$ mimC $_{2} \mathrm{C}_{2} \mathrm{~N}$ on an AET-SAM were both very close to zero and, hence, used the AET-SAM for layering the RTMS for voltammetric measurements. The viscosity and the density of water-saturated RTMSs were measured with an oscillation-type viscometer (VM-10A-M, CBC Materials) and a picnometer at $25^{\circ} \mathrm{C}$, respectively.

For cyclic voltammetric measurements, a gold substrate coated with the SAM of AET was mounted at the bottom of a conical glass cell ${ }^{22}$ with a clamp and an O-ring of $4 \mathrm{~mm}$ diameter. A $2.5 \mu \mathrm{l}$ of the RTMS was placed on top of the SAM at the bottom of the cell. The thickness of the RTMS layer was calculated to be $200 \mu \mathrm{m}$. The cell was then filled with an aqueous electrolyte solution.

The electrochemical cell that we employed is represented by:

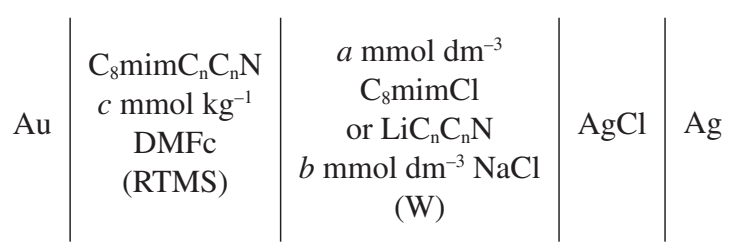

The value of $\Delta_{\mathrm{M}}^{\mathrm{W}} \phi$ was altered by adding either $\mathrm{C}_{8} \mathrm{mim}^{+}$or $\mathrm{C}_{\mathrm{n}} \mathrm{C}_{\mathrm{n}} \mathrm{N}^{-}$ions in W.16,17 The subscript $\mathrm{n}$ in $\mathrm{C}_{8} \operatorname{mimC}_{\mathrm{n}} \mathrm{C}_{\mathrm{n}} \mathrm{N}$ and $\mathrm{LiC}_{\mathrm{n}} \mathrm{C}_{\mathrm{n}} \mathrm{N}$ stands for either 1 or 2 .

Cyclic voltammograms were recorded with a potentiostat (ALS/Chi, Model 600A) using an $\mathrm{Ag}|\mathrm{AgCl}|$ saturated $\mathrm{KCl}$ electrode (SSSE) as the reference electrode and a platinum wire as the counter electrode. The $i R$ drop was compensated for using a positive-feedback circuit equipped in the potentiostat. The aqueous solution in the cell was deaerated with argon bubbling for at least $10 \mathrm{~min}$ prior to the measurement. The

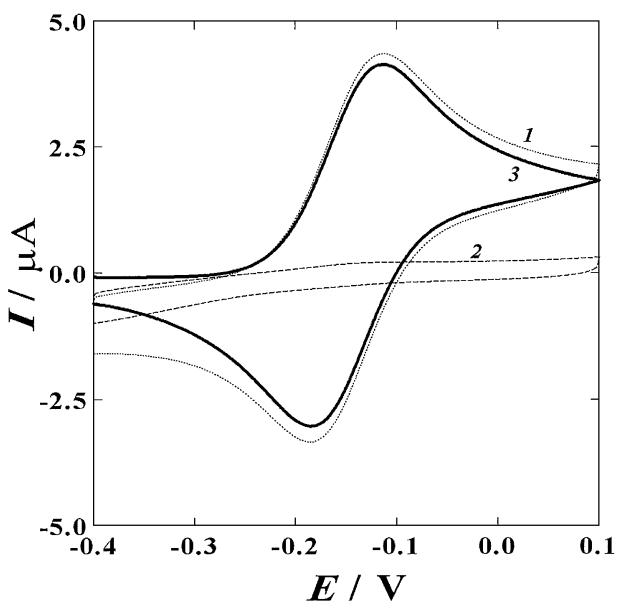

Fig. 1 Cyclic voltammograms recorded with 2-aminoethanethiol SAM-coated $\mathrm{Au}(111)$ covered with a layer of $\mathrm{C}_{8} \mathrm{mimC}_{1} \mathrm{C}_{1} \mathrm{~N}$ with (curve 1) and without $1.3 \mathrm{mmol} \mathrm{kg}{ }^{-1}$ DMFc (curve 2). Curve 3 is the difference between the two curves. Scan rate: $20 \mathrm{mV} \mathrm{s}^{-1}$.

current was taken to be positive when the positive charge was transferred from the RTMS to the $\mathrm{W}$ phase. We note that the sign in this convention is formally opposite to that used in the electrochemistry of liquid-liquid interfaces.

We also tried to form a thinner RTMS layer of about a few micrometer thickness on an AET-SAM with spin-coating. The voltammetry of ferricyanide ions demonstrated that, immediately after spin-coating, the RTMS completely covered the electrode surface. However, after a few hours of the coating, the voltammetric peak for the reduction of ferricyanide became visible. Because the reduction of ferricyanide was not observed in the case of the RTMS layer preequilibrated with an aqueous solution containing $1 \mathrm{mmol} \mathrm{dm}^{-3}$ ferricyanide, the formation of defects, or corrugation in the case of spin-coated RTMS layers, rather than the partition of ferricyanides into the RTMS layer, ${ }^{17,18}$ seemed to be responsible for the observed voltammetric peak of ferricyanides. In this report, we therefore describe only the data obtained with a thick RTMS layer on the AET-SAM-covered gold substrate.

\section{Results and Discussion}

Figure 1 shows a typical example of cyclic voltammograms at a scan rate $(v)$ of $20 \mathrm{mV} \mathrm{s}^{-1}$ when the gold electrode covered with a $\mathrm{C}_{8} \mathrm{mimC}_{1} \mathrm{C}_{1} \mathrm{~N}$ layer with and without containing $\mathrm{DMFc}(c=$ 1.3) (curves 1 and 2, respectively) was in contact with an aqueous solution of $\mathrm{NaCl}(a=0$ and $b=100)$. The negative current at the beginning of the forward scan in the potential range between -0.4 and -0.2 can probably be ascribed to the reduction of oxygen dissolved in the RTMS layer. Curve 3 shows the difference between curves 1 and 2 .

The voltammetric peak in the forward scan in Fig. 1 clearly shows that DMFc was oxidized on the electrode. The appearance of the peak on the reverse scan should correspond to the rereduction of $\mathrm{DMFc}^{+}$generated in the forward scan and confirms that the RTMS | W interface sustained a reverse flow of the current, which was presumably the dissolution of $\mathrm{C}_{1} \mathrm{C}_{1} \mathrm{~N}^{-}$ ions from RTMS to $\mathrm{W}$ and the recombination of $\mathrm{C}_{8} \mathrm{mim}^{+}$ions with $\mathrm{C}_{1} \mathrm{C}_{1} \mathrm{~N}^{-}$to form the bulk RTMS phase.

The peak separation, $68 \mathrm{mV}$, is close to the value of a reversible one-electron redox process. The oxidation was made 

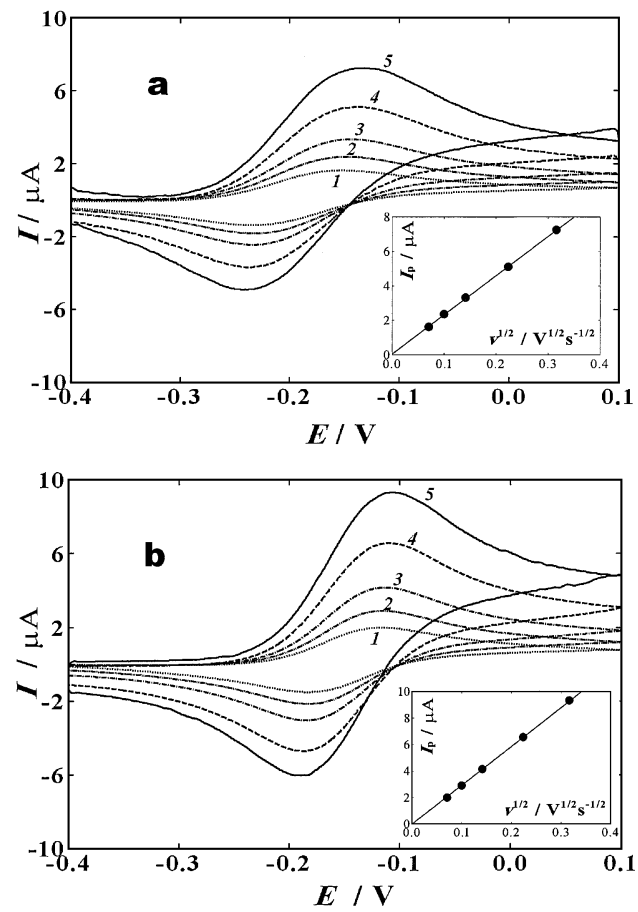

Fig. 2 Cyclic voltammograms recorded with 2-aminoethanethiol SAM-coated $\mathrm{Au}(111)$ covered with a layer of $\mathrm{C}_{8} \operatorname{mimC}_{2} \mathrm{C}_{2} \mathrm{~N}$ containing $2 \mathrm{mmol} \mathrm{kg}-1$ DMFc (panel a) or a layer of $\mathrm{C}_{8} \operatorname{mimC}_{1} \mathrm{C}_{1} \mathrm{~N}$ containing $1.6 \mathrm{mmol} \mathrm{kg}^{-1}$ (b) at the following rates: 5 (curve 1), 10 (curve 2), 20 (curve 3), 50 (curve 4), and 100 (curve 5) $\mathrm{mV} \mathrm{s}^{-1}$. The baseline was subtracted for each curve. The inset in each panel shows the variation of the peak current in the forward scan with the square-root of the scan rate.

possible owing to the concomitant flow of ions across the RTMS | W interface. Because both $\mathrm{Na}^{+}$and $\mathrm{Cl}^{-}$ions are so hydrophilic, they do not dissolve in the RTMS. The oxidation of DMFc primarily accompanied the transfer of $\mathrm{C}_{8} \mathrm{mim}^{+}$ions from RTMS to W. Secondary, the decrease in the concentration of $\mathrm{C}_{\mathrm{n}} \mathrm{C}_{\mathrm{n}} \mathrm{N}^{-}$in $\mathrm{W}$ could contribute to the net current. This is because the flowing out of $\mathrm{C}_{8} \mathrm{mim}^{+}$into $\mathrm{W}$ should decrease the concentration of $\mathrm{C}_{2} \mathrm{C}_{2} \mathrm{~N}^{-}$or $\mathrm{C}_{1} \mathrm{C}_{1} \mathrm{~N}^{-}$ions that were distributed in $\mathrm{W}$ due to the equilibrium partition of $\mathrm{C}_{8} \mathrm{mimC}_{2} \mathrm{C}_{2} \mathrm{~N}$ or $\mathrm{C}_{8} \mathrm{mimC}_{1} \mathrm{C}_{1} \mathrm{~N}$ in $\mathrm{W}$ prior to the voltammetric measurement. The equilibrium concentrations in $\mathrm{W}$ are $1.1 \mathrm{mmol} \mathrm{dm}^{-3}$ $\left(\mathrm{C}_{8} \operatorname{mimC}_{2} \mathrm{C}_{2} \mathrm{~N}\right)$ and $1.8 \mathrm{mmol} \mathrm{dm}^{-3}\left(\mathrm{C}_{8} \mathrm{mimC}_{1} \mathrm{C}_{1} \mathrm{~N}\right)$ at $25^{\circ} \mathrm{C}$, respectively. ${ }^{16,23}$

Figures $2 \mathrm{a}$ and $2 \mathrm{~b}$ show cyclic voltammograms at several scan rates, after a base-line correction was made, when $c=2.1$ for the $\mathrm{C}_{8}$ mimC $_{2} \mathrm{C}_{2} \mathrm{~N}$ layer or $c=1.6$ for the $\mathrm{C}_{8} \mathrm{mimC}_{1} \mathrm{C}_{1} \mathrm{~N}$ layer in contact with the aqueous solution of $\mathrm{NaCl}(a=0$ and $b=100)$. The inset in each panel in Fig. 2 shows that the peak current on the forward scan is proportional to the square root of the scan rate, as is expected in the oxidation of DMFc limited by the diffusion of the DMFc in the RTMS. The absence of a deviation from the straight line at lower scan rates ensures that the RTMS layer was thick enough, so that the semi-infinite diffusion model applies to the transport of DMFc during the electrolysis. From these plots, the diffusion coefficient of DMFc was calculated to be $6.1 \times 10^{-8} \mathrm{~cm}^{2} \mathrm{~s}^{-1}$ in $\mathrm{C}_{8} \mathrm{mimC}_{2} \mathrm{C}_{2} \mathrm{~N}$ and $1.8 \times 10^{-7} \mathrm{~cm}^{2} \mathrm{~s}^{-1}$ in $\mathrm{C}_{8} \mathrm{mimC}_{1} \mathrm{C}_{1} \mathrm{~N}$. The molal concentration of DMFc was converted to the molar concentration using the densities of water-saturated $\mathrm{C}_{8} \mathrm{mimC}_{2} \mathrm{C}_{2} \mathrm{~N}$ and $\mathrm{C}_{8} \mathrm{mimC}_{1} \mathrm{C}_{1} \mathrm{~N}$, being 1.39 and 1.34 ,
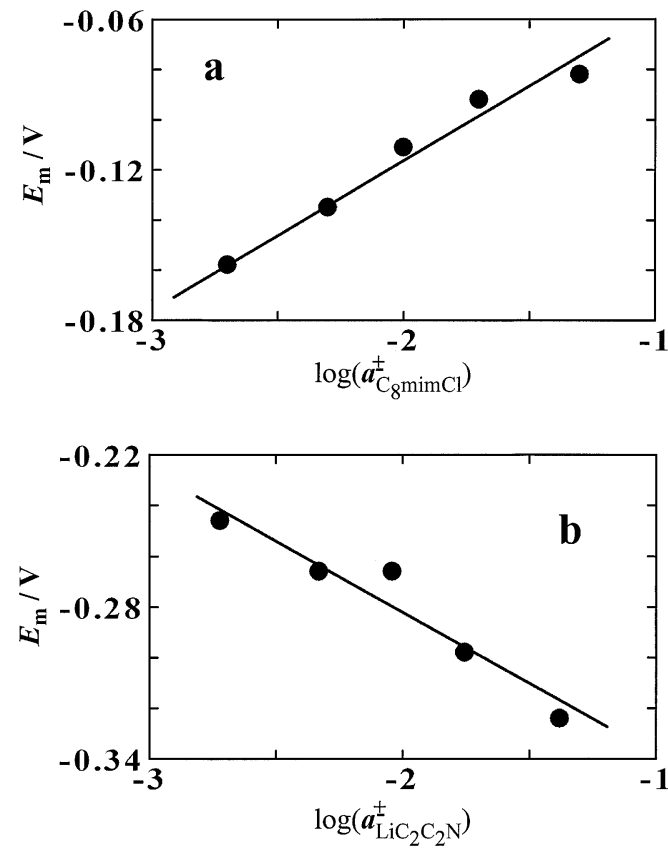

Fig. 3 Variation of the midpoint potential with the mean activity of $\mathrm{C}_{8} \mathrm{mimCl}$ (panel a) or $\mathrm{LiC}_{2} \mathrm{C}_{2} \mathrm{~N}$ (panel b) in $\mathrm{W}$ for the $\mathrm{C}_{8} \mathrm{mimC}_{2} \mathrm{C}_{2} \mathrm{~N}$ layer.

respectively. The diffusion coefficient of DMFc is $1.26 \times 10^{-5}$ $\mathrm{cm}^{2} \mathrm{~s}^{-1}$ in acetonitrile (AN) containing $0.5 \mathrm{~mol} \mathrm{dm}^{-3}$ tetrabutylammonium perchlorate ${ }^{24}$ and $1.8 \times 10^{-5} \mathrm{~cm}^{2} \mathrm{~s}^{-1}(\mathrm{AN}$ in $\left.0.2 \mathrm{~mol} \mathrm{dm}^{-3} \mathrm{NaCF}_{3} \mathrm{SO}_{3}\right),{ }^{25}$ both at $25^{\circ} \mathrm{C}$. The observed smaller diffusion coefficients seem to be ascribed to the high viscosity of the RTMSs.

The viscosities of water-saturated $\mathrm{C}_{8} \operatorname{mimC}_{2} \mathrm{C}_{2} \mathrm{~N}$ and $\mathrm{C}_{8} \mathrm{mimC}_{1} \mathrm{C}_{1} \mathrm{~N}$ were measured to be 108 and $59 \mathrm{mPa} \mathrm{s}$, respectively. On the other hand, the viscosity of $\mathrm{AN}$ at $25^{\circ} \mathrm{C}$ is $0.341 \mathrm{mPa} \mathrm{s} .{ }^{24}$ The ratio of the viscosity of $\mathrm{C}_{8} \mathrm{mimC}_{2} \mathrm{C}_{2} \mathrm{~N}$ to that of $\mathrm{AN}$ is then 317 . This factor is roughly equal to the ratio of the diffusion coefficients, 295 or 207; Walden's rule applies to the diffusion in the RTMSs. In the case of the $\mathrm{C}_{8} \mathrm{mimC}_{1} \mathrm{C}_{1} \mathrm{~N}$ layer, the ratio of the viscosities is 174 , which is also of the same magnitude on the order as the ratio of the diffusion coefficients, 100 or 80 .

The midpoint potential $\left(E_{\mathrm{m}}\right)$ of the voltammograms in Fig. 2 was little dependent on the scan rate for both the $\mathrm{C}_{8} \mathrm{mimC}_{2} \mathrm{C}_{2} \mathrm{~N}$ and $\mathrm{C}_{8} \mathrm{mimC}_{1} \mathrm{C}_{1} \mathrm{~N}$ layers, $-0.19 \mathrm{~V}$ and $-0.15 \mathrm{~V}$, respectively. This difference reflects the difference between the values of $\Delta_{\mathrm{M}}^{\mathrm{W}} \phi$ at the two interfaces, $\mathrm{C}_{8} \mathrm{mimC}_{2} \mathrm{C}_{2} \mathrm{~N} \mid \mathrm{W}$ and $\mathrm{C}_{8} \mathrm{mimC}_{1} \mathrm{C}_{1} \mathrm{~N}$ | W. The equilibrium value of $\Delta_{\mathrm{M}}^{\mathrm{W}} \phi$ for the partition of $1: 1$ salt $\left(\mathrm{C}^{+} \mathrm{A}^{-}\right)$is given by ${ }^{16}$

$$
\Delta_{\mathrm{M}}^{\mathrm{W}} \phi=\frac{\Delta_{\mathrm{M}}^{\mathrm{W}} \phi_{\mathrm{C}^{+}}^{0}+\Delta_{\mathrm{M}}^{\mathrm{W}} \phi_{\mathrm{A}^{-}}^{0}}{2},
$$

where $\Delta_{\mathrm{M}}^{\mathrm{W}} \phi_{\mathrm{i}}^{0}$ is the standard ion transfer potential of ion i. The difference in $\Delta_{\mathrm{M}}^{\mathrm{W}} \phi$ between the two interfaces is then,

$$
\begin{aligned}
\Delta_{\mathrm{M}}^{\mathrm{W}} \phi\left(\mathrm{C}_{8} \operatorname{mimC}_{2} \mathrm{C}_{2} \mathrm{~N} \mid \mathrm{W}\right)-\Delta_{\mathrm{M}}^{\mathrm{W}} \phi\left(\mathrm{C}_{8} \operatorname{mimC}_{1} \mathrm{C}_{1} \mathrm{~N} \mid \mathrm{W}\right)= \\
\frac{\Delta_{\mathrm{M}}^{\mathrm{W}} \phi_{\mathrm{C}_{2} \mathrm{C}_{2} \mathrm{~N}}^{0}-\Delta_{\mathrm{M}}^{\mathrm{W}} \phi_{\mathrm{C}_{1} \mathrm{C}_{1} \mathrm{~N}}^{0}}{2} .
\end{aligned}
$$

The observed difference in $E_{\mathrm{m}}$ of $40 \mathrm{mV}$ is in line with the fact 

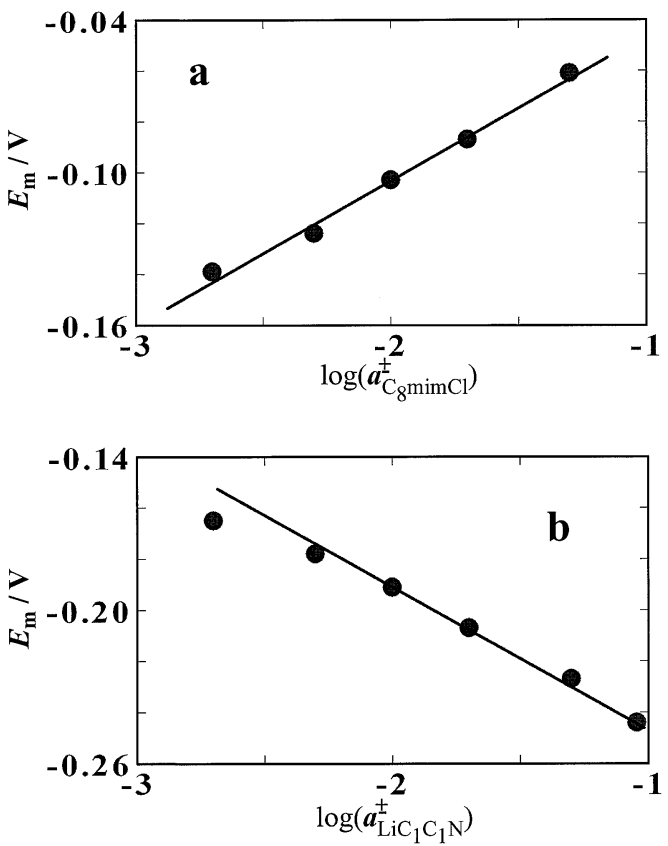

Fig. 4 Variation of the midpoint potential with the mean activity of $\mathrm{C}_{8} \mathrm{mimCl}$ (panel a) or $\mathrm{LiC}_{1} \mathrm{C}_{1} \mathrm{~N}$ (panel b) in $\mathrm{W}$ for the $\mathrm{C}_{8} \mathrm{mimC}_{1} \mathrm{C}_{1} \mathrm{~N}$ layer.

that $\mathrm{C}_{2} \mathrm{C}_{2} \mathrm{~N}^{-}$is more hydrophobic than $\mathrm{C}_{1} \mathrm{C}_{1} \mathrm{~N}^{-}$, as reflected by the difference in the width of the polarized potential windows of the RTMS | W interfaces for the tetrahexylammonium salts of $\mathrm{C}_{2} \mathrm{C}_{2} \mathrm{~N}^{-}$and $\mathrm{C}_{1} \mathrm{C}_{1} \mathrm{~N}^{-}$, that is, $50 \mathrm{mV} .{ }^{26}$

We next added to $\mathrm{W}$ different concentrations of $\mathrm{C}_{8} \mathrm{mimCl}$ or $\mathrm{LiC}_{\mathrm{n}} \mathrm{C}_{\mathrm{n}} \mathrm{N}$, and examined the shift in the $E_{\mathrm{m}}$ values. The results are shown in Figs. $3 \mathrm{a}$ and $3 \mathrm{~b}$ for $\mathrm{C}_{8} \mathrm{mimC}_{2} \mathrm{C}_{2} \mathrm{~N}$ and in Figs. $4 \mathrm{a}$ and $4 \mathrm{~b}$ for $\mathrm{C}_{8} \mathrm{mimC}_{1} \mathrm{C}_{1} \mathrm{~N}$ as a function of the mean ionic activity of the corresponding electrolyte in $\mathrm{W}$. The straight lines in Figs. 3a, 3b, 4a, and 4b have slopes of 60, 56, 59 and $55 \mathrm{mV}$ per decade, respectively. In all cases, $E_{\mathrm{m}}$ thus responds to the potential determining ion, as predicted by the Nernst equation. This confirms that $\Delta_{\mathrm{M}}^{\mathrm{W}} \phi$ is determined by the distribution in RTMS and $\mathrm{W}$ of the potential-determining ion that constitutes the RTMS, as has been predicted $^{17}$ and confirmed potentiometrically. ${ }^{16}$

The results in Figs. 1 and 2 appear to show that the interface between the RTMS and the aqueous $0.1 \mathrm{~mol} \mathrm{dm}^{-3} \mathrm{NaCl}$ enables the transfer of the current passively, depending on the magnitude of the redox reaction on the electrode, and thus acts as a reference interface, as is the case of a liquid | liquid interface, where the ions common to both phases determine the phase boundary potential. ${ }^{27,28}$ The peak separation, however, becomes wider with increasing the scan rate from $84 \mathrm{mV}$ at 5 $\mathrm{mV} \mathrm{s}^{-1}$ to $110 \mathrm{mV}$ at $100 \mathrm{mV} \mathrm{s}^{-1}$ in the case of $\mathrm{C}_{8} \mathrm{mimC}_{2} \mathrm{C}_{2} \mathrm{~N}$. The redox reaction of DMFc in organic solvents is reversible or quasi-reversible; ${ }^{24,25}$ taking account of the factor of 100 for the smaller diffusion coefficient of DMFc in the RTMS, we may assume that the electrode reaction of DMFc at the electrode is reversible within the range of the scan rate employed, though the rate of the oxidation of ferrocene in 1-butyl-3methylimidazolium $\mathrm{C}_{1} \mathrm{C}_{1} \mathrm{~N}$ is reported to be one order of magnitude smaller than in AN. ${ }^{29}$ The broad peak separation observed should therefore be attributed to other sources. One possible factor is the presence of the uncompensated resistance, since the positive feedback method tends to undercompensate the $i R$ drop to avoid possible oscillation during the measurement. A second possibility is that the electrochemical reversibility of the RTMS | W interface is not ideal, and the ion transfer may give rise to a certain resistive contribution.

In the case of the $\mathrm{C}_{8} \mathrm{mimC}_{1} \mathrm{C}_{1} \mathrm{~N}$ layer, the peak separations at 5 and $100 \mathrm{mV} \mathrm{s}^{-1}$ were 66 and $78 \mathrm{mV}$, which were distinctively narrower than that for the $\mathrm{C}_{8} \operatorname{mimC}_{2} \mathrm{C}_{2} \mathrm{~N}$ layer. This suggests that the reversibility at $\mathrm{C}_{8} \mathrm{mimC}_{1} \mathrm{C}_{1} \mathrm{~N} \mid \mathrm{W}$ interface, rather than the uncompensated resistance, is better than that at the $\mathrm{C}_{8} \mathrm{mimC}_{2} \mathrm{C}_{2} \mathrm{~N} \mid \mathrm{W}$, a more hydrophobic RTMS. ${ }^{26}$ In fact, as a first approximation, the polarizability of the RTMS I W interface is directly related to the solubility product of the RTMS. ${ }^{30}$ The reversible transfer of the cation $\mathrm{C}^{+}$and the anion $\mathrm{A}^{-}$that constitute the RTMS into $\mathrm{W}$ containing a sufficient amount of supporting electrolytes leads to the dimensionless polarization resistance at null current, $R:^{30}$

$$
R \propto \delta+1-\frac{2\left(t_{C^{\mathrm{M}}}^{\mathrm{M}}\right)^{2}}{\delta+1} \simeq \delta
$$

where $t_{\mathrm{C}^{+}}^{\mathrm{M}}$ is the transference number of $\mathrm{C}^{+}$in the RTMS phase, $\mathrm{M}$, and $\delta$ is given by

$$
\delta=\left(\frac{D^{\mathrm{M}}}{D_{\mathrm{C}^{+}}^{\mathrm{W}}}\right)^{1 / 2}\left(\frac{D_{\mathrm{C}^{+}}^{\mathrm{W}}}{D_{\mathrm{A}^{-}}^{\mathrm{W}}}\right)^{1 / 4} \exp \left[\frac{F}{2 R T}\left(\Delta_{\mathrm{M}}^{\mathrm{W}} \phi_{\mathrm{A}^{-}}^{0}-\Delta_{\mathrm{M}}^{\mathrm{W}} \phi_{\mathrm{C}^{+}}^{0}\right)\right] .
$$

Here, $D^{\mathrm{M}}$ is the composite diffusion coefficient of the salt CA in $\mathrm{M}, D_{\mathrm{i}}^{\mathrm{W}}$ is the diffusion coefficient of $\mathrm{i}\left(\mathrm{i}=\mathrm{C}^{+}\right.$or $\left.\mathrm{A}^{-}\right)$in $\mathrm{W}, \Delta_{\mathrm{M}}^{\mathrm{W}} \phi_{\mathrm{i}}^{0}$ is the standard ion transfer potential of ion $\mathrm{i}$ between $\mathrm{M}$ and $\mathrm{W},{ }^{16} F$ is the Faraday constant, $R$ is the gas constant, and $T$ is the absolute temperature. Furthermore, the solubility product of $\mathrm{CA}, K_{\mathrm{sp}}^{\mathrm{W}}$, is related to the standard ion transfer potentials of these ions through: ${ }^{16}$

$$
K_{\mathrm{sp}}^{\mathrm{W}}=\exp \left[\frac{F}{R T}\left(\Delta_{\mathrm{M}}^{\mathrm{W}} \phi_{\mathrm{A}^{-}}^{0}-\Delta_{\mathrm{M}}^{\mathrm{W}} \phi_{\mathrm{C}^{+}}^{0}\right)\right] .
$$

Then,

$$
R \propto \sqrt{K_{\mathrm{sp}}^{\mathrm{W}}} .
$$

Thus, the higher solubility of $\mathrm{C}_{8} \mathrm{mimC}_{1} \mathrm{C}_{1} \mathrm{~N}$ than $\mathrm{C}_{8} \mathrm{mimC}_{2} \mathrm{C}_{2} \mathrm{~N}$ in $\mathrm{W}$ can explain the fact that the polarization resistance of the $\mathrm{C}_{8} \mathrm{mimC}_{1} \mathrm{C}_{1} \mathrm{~N}$ | W interface is smaller than that at the $\mathrm{C}_{8} \mathrm{mimC}_{2} \mathrm{C}_{2} \mathrm{~N} / \mathrm{W}$ interface.

\section{Conclusions}

A new electrode composed of $\mathrm{Au}(111)$ covered with a hydrophobic RTMS layer of about $200 \mu \mathrm{m}$ thickness was interfaced with a self-assembled monolayer of 2-aminoethane thiolates. The RTMS | W interface functions as a reference interface when the current density is low. This is promising when using RTMSs for sensors and other devices, in that a nonvolatile and sparingly soluble thin layer of an RTMS has well-defined electrochemical properties. Conversely, the potentiometric reversibility of the RTMS | W interface is shown to be readily inferred by voltammetric techniques. The limited reversibility of the RTMS | W interface is, however, taken into account in quantitatively understanding of the voltammetric behavior. 


\section{Acknowledgements}

This work was supported by a Grant-in-Aid for Scientific Research (No. 14205120) and a Grant-in-Aid for Exploratory Research (No. 15655008) from the Ministry of Education, Culture, Sports, Science, and Technology, Japan. The present work was conducted under the program: Center of Excellence for United Approach to New Materials Science, Kyoto University.

\section{References}

1. C. Shi and F. C. Anson, J. Phys. Chem. B, 1998, 102, 9850.

2. C. Shi and F. C. Anson, Anal. Chem., 1998, 70, 3114.

3. C. Shi and F. C. Anson, J. Phys. Chem. B, 1999, 103, 6283.

4. H. O. Shafer, T. L. Derback, and C. A. Koval, J. Phys. Chem. B, 2000, 104, 1025.

5. C. Shi and F. C. Anson, J. Phys. Chem. B, 2001, 105, 1047.

6. T. D. Chung and F. C. Anson, Anal. Chem., 2001, 73, 337.

7. S. M. Ulmeanu, H. Hensen, Z. Samec, G. Bouchard, P.-A. Carrupt, and H. H. Girault, J. Electroanal. Chem., 2002, 530, 10.

8. H. Park, T. Higuchi, S. Okazaki, and M. Oyama, J. Electroanal. Chem., 2002, 518, 27.

9. K. Nakatani, T. Uchida, H. Misawa, N. Kitamura, and H. Masuhara, J. Phys. Chem., 1993, 97, 5197.

10. F. Scholz, S. Komorsky-Lovric, and M. Lovric, Electrochem. Commun., 2000, 2, 112

11. S. Ulmeanu, H. J. Lee, D. J. Fermin, H. H. Girault, and Y. H. Shao, Electrochem. Commun., 2001, 3, 219.

12. F. Marken, D. D. Webster, S. D. Bull, and S. G. Davies, J. Electroanal. Chem., 1997, 437, 209.

13. T. Kakiuchi, Electrochim. Acta, 1998, 44, 171.
14. N. Ichieda, O. Shirai, M. Kasuno, K. Banu, A. Uehara, Y. Yoshida, and S. Kihara, J. Electroanal. Chem., 2003, 542, 97.

15. J. C. Myland and K. B. Oldham, J. Electroanal. Chem., 2002, 530, 1 .

16. T. Kakiuchi, N. Tsujioka, S. Kurita, and Y. Iwami, Electrochem. Commun., 2003, 5, 159.

17. B. M. Quinn, Z. Ding, R. Moulton, and A. J. Bard Langmuir, 2002, 18, 1734.

18. J. Wadhawan, U. Schröder, A. Neudeck, S. J. Wilkins, R G. Compton, F. Marken, C. S. Consorti, R. F. de Souza, and J. Dupont, J. Electroanal. Chem., 2000, 493, 75.

19. C. M. Fordon, J. D. Holbrey, A. R. Kennedy, and K. R Seddon, J. Mater. Chem., 1998, 8, 2627.

20. Y. Iwami, D. Hobara, M. Yamamoto, and T. Kakiuchi, $J$. Electroanal. Chem., 2004, 564, 77

21. S. Carda-Broch, A. Berthod, and D. W. Armstrong, Anal. Bioanal. Chem., 2003, 375, 191.

22. C. A. Widrig, C. Chung, and M. D. Porter, J. Electroanal. Chem., 1991, 310, 335.

23 T. Yoshimatsu, N. Nishi, and T. Kakiuchi, unpublished results.

24. M. Matsumoto and T. W. Swaddle, Inorg. Chem., 2004, 43, 2724.

25. C. R. Cabrera and A. J. Bard, J. Electroanal. Chem., 1989 273, 147.

26. T. Kakiuchi, N. Tsujioka, K. Sueishi, N. Nishi, and M. Yamamoto, Electrochemistry, in press.

27. L. Q. Hung, J. Electroanal. Chem., 1980, 115, 159

28. T. Kakiuchi and M. Senda, Bull. Chem. Soc. Jpn., 1987, 60, 3099.

29. C. Lagrost, D. Carrie, M. Vaultier, and P. Hapiot, J. Phys. Chem. A, 2003, 107, 745 .

30. T. Kakiuchi and N. Tsujioka, to be published. 